\title{
Testing Activities of Daily Living (ADL) in Patients with Age-Related Macular Degeneration Undergoing Cataract Surgery: Lessons Learned from the Past and Development of a New Quality of Life (QOL) Test
}

\author{
Andreas F Borkenstein (D)', Eva-Maria Borkenstein', Karen Murphy², Susan A Primo $\mathbb{D}^{3}$ \\ 'Borkenstein \& Borkenstein, Private Practice and Privatklinik der Kreuzschwestern, Graz, 80 I0, Austria; ${ }^{2}$ VisionWorks Rehabilitation, LLC, Novi, MI, \\ 48374, USA; ${ }^{3}$ Emory University School of Medicine, Department of Ophthalmology, Atlanta, GA, 30322, USA
}

Correspondence: Andreas F Borkenstein, Borkenstein \& Borkenstein, Private Practice and Privatklinik der Kreuzschwestern, Kreuzgasse 35, Graz, 8010 , Austria, Tel +433163313880, Email crustalith@gmx.at

Age-related macular degeneration (AMD) is the leading cause of severe, permanent visual impairment and blindness in people over the age of 60 . The World Health Organization (WHO) estimates that $8.7 \%$ of global blindness is caused by AMD. The financial burden is enormous with global costs of visual impairment reaching US $\$ 343$ billion. In 2020 , estimated 15.2 million people aged over 50 years were blind worldwide, and an additional 78.8 million had moderate-tosevere vision impairment due to cataracts. ${ }^{1}$ Cataract and age-related macular degeneration are common causes of decreased vision, causing visual impairment that often occurs simultaneously. Although modern cataract surgery is a safe and effective treatment for cataract-induced visual loss, some ophthalmologists have had fear in the past that surgery could worsen macular degeneration. This has been disproven by various studies in the past. ${ }^{2,3}$ It was shown that Quality of Life (QOL) benefits were predominant in the group that underwent cataract surgery and that there was no increased risk of progression of maculopathy. ${ }^{4}$ Recent clinical and scientific evidence does not find cataract surgery to cause or worsen AMD. ${ }^{5}$ Nevertheless, the reduced prognosis and possible effects should be discussed in detail with the patients already preoperatively.

The purpose of low-vision rehabilitation is to allow people to resume performing activities of daily living skills (ADLs) and achieving self-autonomy through improved quality of life (QOL), with reading being one of the most important tasks. ${ }^{6}$ This is achieved by special training (neuroadaptation) in the use of assistive technology by prescribing appropriate devices, which range from basic magnifiers to high-magnification video-magnifiers to smartphones and tablets to virtual and augmented reality tools. ${ }^{7}$

Intraocular vision-improving devices, such as the Implantable Miniature Telescopes (IMT) and intraocular lens (IOL) implants, may be superior to external devices for improving vision in patients with AMD because they provide a more intuitive technology with respect to head motion, vestibular ocular reflex adaptation, and monocular depth perception. ${ }^{8-11}$ However, challenges may remain, for some patients, with adaptation to new bi-ocular vision status.

In the past, it has been shown that cost and rehabilitation time are factors in patient management with intraocular devices. Patients require much more intensive care both pre- and post-implantation, including additional controls and evaluations. Technological improvements and developments have made these implants safer and the procedure itself less dangerous with reduced post-operative sequelae. Therefore, it has become apparent that the limiting factor is not so much of the actual surgery but rather the patient selection and rehabilitation process. It has been shown that these cases are complex and should never be routine interventions.

We were also able to show in a multicenter study that testing with conventional visual acuity tests, such as the standard Snellen and Early Treatment Diabetic Retinopathy Study (ETDRS) charts, may be less predictive in determining 
optimal patient satisfaction and improved QOL outcomes. It seems more logical to also include testing of ADLs evaluating tasks that influence QOL and self-autonomy. This could be proven in our clinical case series as well as experienced in conventional cases when caring for visually impaired patients. ${ }^{12-14}$

There are multiple intraocular vision-improving devices available for intervention in patients with moderate-to-severe AMD. While these advances in technology can offer hope to many patients, it is difficult to predict how well the results in the clinical literature will generalize to actual practice, thus limiting the number of surgical cases. Therefore, it could be shown in the past that even innovative, new technologies are not frequently used in the long term after initial euphoria and description of excellent results in case series. There were various examples that illustrate this in the past. Newly developed devices and intraocular lenses that achieved very good results in the first case series after market launch. However, due to the high effort in patient management and pre-postoperative care, they were too costly and were subsequently no longer used. Thinking about the high number of cases of cataract and AMD patients, this is a sad and unsatisfactory fact.

Therefore, we have established this initiative, an American-European collaboration with low-vision rehabilitation specialists, to design a novel testing method tailored for AMD patients undergoing cataract surgery. The hope is to change the approach to this topic, by developing an "ADL-test kit" that is achieving objective results in a time-saving, user-friendly and easy way. The aim of this new "ADL-test kit" is to evaluate the "real life condition" before and after surgery as objectively and comparably as possible.

The ADL test kit contains both a theoretical and a practical part, it should cover the whole spectrum and also offer forensic advantages, as it gives a good overall picture of the current condition. The ADL-test kit includes a combined patient-reported questionnaire/performance-based measure, depression scale and a cognitive test.

In the practical part, everyday activities and skills are tested using components that are integrated in the test-kit (suitcase). Patients are assessed on their ability to complete basic tasks. This involves, eg cutting a soft mass into equalsized pieces or pouring a defined amount of liquid into a small opening. This also includes recognizing pictures or drawing/giving a signature in a pre-marked space and operating with a cell phone dummy.

It is important to understand the priorities and goals of each individual to ensure that the device recommendations and strategies provided will align with their expectations.

Therefore, the focus of the patient-reported questionnaire is to identify the patient's priorities, the importance placed on a specific task and their perceived functional limitation. The items in the performance-based measure include ADL tasks considered to be visually demanding such as reading, writing and measuring. ${ }^{12,15,16}$ The examiner provides the items needed for the test to ensure standardization of performance and the tasks are scored using standardized descriptive criteria.

Previous studies have shown that cognitive impairment and depression may affect activity participation in older adults and compromise success and satisfaction. ${ }^{17-19}$ Rather than relying on self-reports, we felt that including brief screening tests that are easy to administer would provide objective measurements of the patient's psychosocial status.

This should also provide ophthalmologists and optometrists forensic certainty that the devices are working in first case series or scientific studies as well as in clinical routine. Most importantly, it would also give the affected patients a good overview and objectively show the condition/status between before and after surgery. In addition, new innovations and developments (eg, new AMD devices) could be better evaluated in multicenter clinical trials, as there would be better objective comparability.

As the first results were so positive and promising, the development of these ADL-test kits seems so important to us that we want to inform our colleagues directly with this Scientific Letter. A detailed description of the newly developed ADL test kit and first clinical data will follow soon.

\section{Disclosure}

Mrs Karen Murphy reports personal fees from Samsara Vision, Inc. The authors report no other conflicts of interest in this work. 


\section{References}

1. Steinmetz JD, Bourne RRA, Briant PS; GBD 2019 Blindness and Vision Impairment Collaborators; Vision Loss Expert Group of the Global Burden of Disease Study. Causes of blindness and vision impairment in 2020 and trends over 30 years, and prevalence of avoidable blindness in relation to VISION 2020: the Right to Sight: an analysis for the Global Burden of Disease Study. Lancet Glob Health. 2021;9(2):e144-e160. doi:10.1016/S2214-109X(20)30489-7

2. Bhandari S, Vitale S, Agrón E, Clemons TE, Chew EY; AREDS2 Research Group. Cataract surgery and the risk of developing late age-related macular degeneration: the Age-Related Eye Disease Study 2 Report Number 27. Ophthalmology. 2021:S0161-6420(21)00901-5. doi:10.1016/j. ophtha.2021.11.014

3. Lamoureux EL, Hooper CY, Lim L, et al. Impact of cataract surgery on quality of life in patients with early age-related macular degeneration. Optom Vis Sci. 2007;84(8):683-688. doi:10.1097/OPX.0b013e31812f755f

4. Armbrecht AM, Findlay C, Aspinall PA, Hill AR, Dhillon B. Cataract surgery in patients with age-related macular degeneration: one-year outcomes. J Cataract Refract Surg. 2003;29(4):686-693. doi:10.1016/s0886-3350(02)01650-4

5. Ehmann DS, Ho AC. Cataract surgery and age-related macular degeneration. Curr Opin Ophthalmol. 2017;28(1):58-62. doi:10.1097/ ICU.0000000000000331

6. van Nispen RM, Virgili G, Hoeben M, et al. Low vision rehabilitation for better quality of life in visually impaired adults. Cochrane Database Syst Rev. 2020;1(1):CD006543. doi:10.1002/14651858.CD006543

7. Virgili G, Acosta R, Bentley SA, Giacomelli G, Allcock C, Evans JR. Reading aids for adults with low vision. Cochrane Database Syst Rev. 2018;4 (4):CD003303. doi:10.1002/14651858.CD003303.pub4

8. Grzybowski A, Wang J, Mao F, Wang D, Wang N. Intraocular vision-improving devices in age-related macular degeneration. Ann Transl Med. 2020;8(22):1549. doi:10.21037/atm-20-5851

9. Gupta A, Lam J, Custis P, Munz S, Fong D, Koster M. Implantable miniature telescope (IMT) for vision loss due to end-stage age-related macular degeneration. Cochrane Database Syst Rev. 2018;5(5):CD011140. doi:10.1002/14651858.CD011140.pub2

10. Hau VS, London N, Dalton M. The treatment paradigm for the implantable miniature telescope. Ophthalmol Ther. 2016;5(1):21-30. doi:10.1007/ s40123-016-0047-5

11. Boyer D, Freund KB, Regillo C, Levy MH, Garg S. Long-term (60-month) results for the implantable miniature telescope: efficacy and safety outcomes stratified by age in patients with end-stage age-related macular degeneration. Clin Ophthalmol. 2015;9:1099-1107. doi:10.2147/OPTH. S86208

12. Borkenstein AF, Borkenstein EM, Persson S, Muus G, Nielsen NV. Improving outcomes for patients with age-related macular degeneration and cataracts: the importance of including an assessment of Activities of Daily Life (ADL). Clin Ophthalmol. 2021;15:3333-3339. doi:10.2147/OPTH. S327274

13. Higgins BE, Taylor DJ, Bi W, Binns AM, Crabb DP. Novel computer-based assessments of everyday visual function in people with age-related macular degeneration. PLoS One. 2020;15(12):e0243578. doi:10.1371/journal.pone.0243578

14. Taylor DJ, Smith ND, Jones PR, Binns AM, Crabb DP. Measuring dynamic levels of self-perceived anxiety and concern during simulated mobility tasks in people with non-neovascular age-related macular degeneration. Br J Ophthalmol. 2020;104(4):529-534. doi:10.1136/bjophthalmol-2019313864

15. Lamoureux E, Hassell JB, Keeffe JE. The determinants of participation in activities of daily living in people with impaired vision. Am $J$ Ophthalmol. 2004;137:265-270. doi:10.1016/j.ajo.2003.08.003

16. Snow M, Warren M, Yuen HK. Revised Self-Report Assessment of Functional Visual Performance (R-SRAFVP) - part II: construct validation. Am J Occup Ther. 2018;72(5):7205205020p1-7205205020p8. doi:10.5014/ajot.2018.030205

17. Perlmutter MS, Bhorade A, Gordon M, Hollingsworth HH, Baum MC. Cognitive, visual, auditory, and emotional factors that affect participation in older adults. Am J Occup Ther. 2010;64(4):570-579. doi:10.5014/ajot.2010.09089

18. Whitson HE, Ansah D, Whitaker D, et al. Prevalence and patterns of comorbid cognitive impairment in low vision rehabilitation (LVR) for macular disease. Arch Gerontol Geriatr. 2010;50(2):209. doi:10.1016/j.archger.2009.03.010

19. Goldstein JE, Chun MW, Fletcher DC, Deremeik T, Massof RW. Visual ability of patients seeking outpatient low vision services in the United States. JAMA Ophthalmol. 2014;132(10):1169-1177. doi:10.1001/jamaophthalmol.2014.1747

Clinical Ophthalmology

Dovepress

\section{Publish your work in this journal}

Clinical Ophthalmology is an international, peer-reviewed journal covering all subspecialties within ophthalmology. Key topics include: Optometry; Visual science; Pharmacology and drug therapy in eye diseases; Basic Sciences; Primary and Secondary eye care; Patient Safety and Quality of Care Improvements. This journal is indexed on PubMed Central and CAS, and is the official journal of The Society of Clinical Ophthalmology (SCO). The manuscript management system is completely online and includes a very quick and fair peer-review system, which is all easy to use. Visit http://www. dovepress.com/testimonials.php to read real quotes from published authors.

Submit your manuscript here: https://www.dovepress.com/clinical-ophthalmology-journal 